\title{
THE LEFT-SIDED SUPERIOR VENA CAVA
}

\author{
BY \\ MAURICE CAMPBELL AND D. C. DEUCHAR \\ From the Cardiac Department, Guy's Hospital, and the Institute of Cardiology
}

Received June 12, 1954

Abnormalities of the main systemic and pulmonary veins are arousing increasing interest. The object of this paper is to review our experience of 46 cases of the left-sided superior vena cava, including 4 examples of the much rarer condition where the inferior vena cava is absent. We wish also to discuss the type of cases in which these occur and their clinical significance.

Abnormal drainage of the pulmonary veins has been discussed in several recent papersdrainage into the left superior vena cava by Snellen and Albers (1952), Gardner and Oram (1953), and Whitaker (1954), and drainage into the right atrium and the right side generally by Brody (1942), Smith (1951), Edwards (1953), and Swan et al. (1953). These groups will not, therefore, be included here, especially as we have seen few examples of the former.

\section{EMBRYOLOGY}

The relevant embryology will be reviewed shortly to help in understanding these abnormalities.

The Left-sided Superior Vena Cava. At one stage in the formation of the human embryo the sinu-atrial chamber becomes differentiated into the sinus venosus and the atrial chamber; and the septum dividing the latter into the right and left parts is formed in such a way that the sinus venosus communicates with the right part only. The sinus venosus lies transversely, dorsal to the atrial part of the heart, and its lateral parts are known as the horns, into each of which a duct of Cuvier opens. This is formed by the union of an anterior and a posterior cardinal vein, the former of these draining blood from the cephalic end and the latter from the caudal end of the embryo (Fig. 1). As development proceeds the heart as a whole moves caudally into the thorax

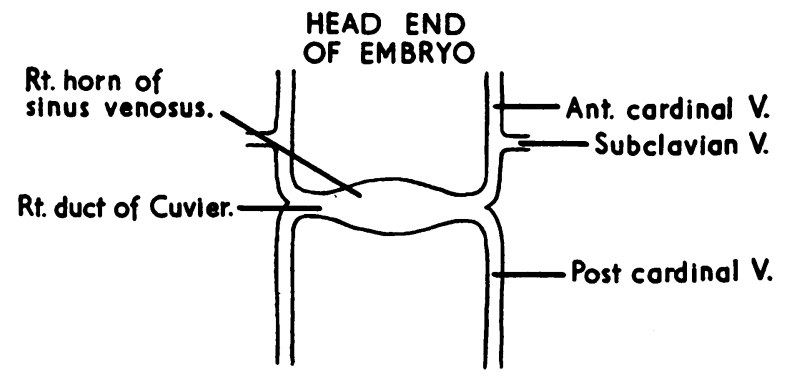

FIG. 1.-Diagram showing an early symmetrical stage of the sinus venosus, the ducts of Cuvier, and the anterior and posterior cardinal veins on both sides.

so that the ducts of Cuvier come to lie almost in the long axis of the embryo, draining from the cephalic end towards the heart. About the same time as the development of the liver and the common hepatic vein which drains into the right sinus horn, this half of the sinus venosus becomes larger than the left, and a transverse communication develops between the anterior cardinal veins so that the arrangement becomes as depicted in Fig. 2. 


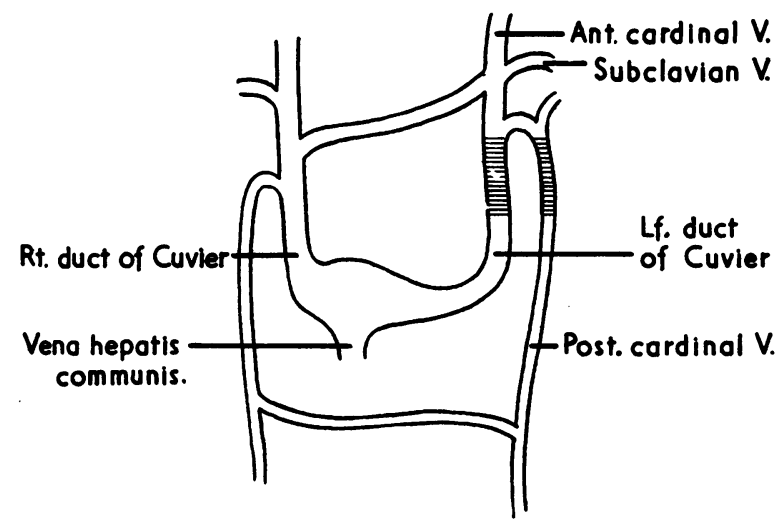

FIG. 2.-Diagram showing the right side of the sinus venosus developing into the right atrium and the ducts of Cuvier turning at right angles to this. The anterior and posterior cardinal veins have developed cross communications and the hepatic vein has appeared.

Ultimately the sinus venosus is absorbed into the structure of the right atrium; the communication between the two anterior cardinal veins becomes the left innominate vein, and the left cardinal vein becomes occluded between the innominate vein and the duct of Cuvier; the left duct of Cuvier and the left sinus horn become respectively the oblique vein of the left atrium (of Marshall) and the coronary sinus; and the right anterior cardinal vein and duct of Cuvier become the superior vena cava (Fig. 3).

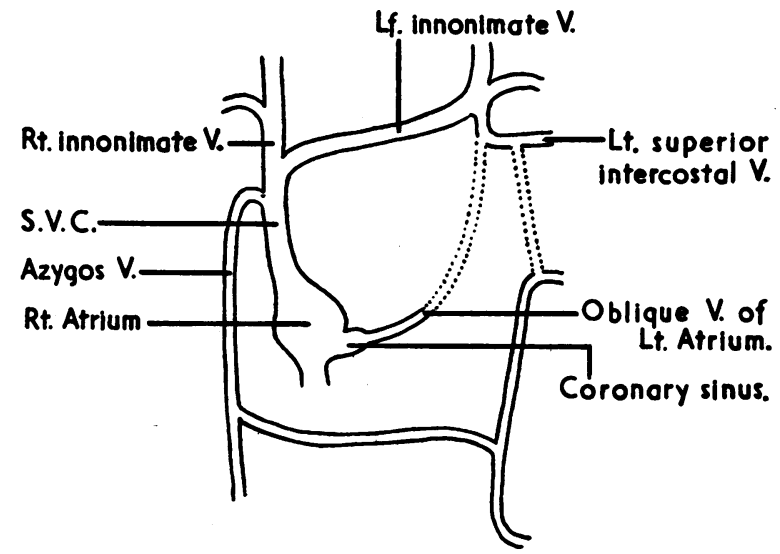

FIG. 3.-Diagram of a later stage with the left anterior cardinal vein obliterated, with the left duct of Cuvier becoming the oblique vein of the left atrium, and the left horn of the sinus venosus becoming the coronary sinus. The right azygos vein now passes into the right superior vena cava and the corresponding communication on the left side has become obliterated.

Comment. If the left cardinal vein does not become occluded, this vessel persists as a left-sided superior vena cava (S.V.C.) draining through the coronary sinus into the right atrium. This occurs normally in some animals and occasionally in man, generally with other developmental abnormalities. 
Apart from this-the common type of left S.V.C.--there is another possible type, where the S.V.C. lies on the left side in association with mirror image dextrocardia and complete situs inversus; this is comparatively straightforward or would be if it was not so common for the heart to be transposed without the abdominal viscera or vice versa. In fact, the important question in these cases is whether the venous atrium and the superior vena cava are transposed or not, and though they tend to follow the abdominal viscera they do not always do so and may instead follow the rest of the heart. Generally, in these cases, the S.V.C. is not merely unilateral and a mirror image of the normal but bilateral.

When the atrium is undivided or incompletely divided and the left S.V.C. drains into its left side (a condition that we have seen 5 times), the normal development has been arrested earlier and is seems that the sinus venosus has persisted and not been absorbed into the right atrium as usual. We have not seen a case where a left S.V.C. drains into an otherwise normal left atrium to produce a veno-arterial shunt.

It is clear from this description of the embryology that in normal development the bilateral symmetrical arrangement of the veins has to change to a unilateral and asymmetrical pattern and a failure to achieve this normally appears to be responsible both for the left-sided S.V.C. and for partial transposition of the heart or abdominal viscera and for their frequent association. Among our cases a left-sided S.V.C. was present in over 40 per cent. of those with partial transposition and in only 2 per cent of other cases of congenital heart disease. This makes it clear that some common or closely related factors are responsible for the production of transposition of the viscera and also of a left-sided superior vena cava, alone or with a second vena cava on the right. Speaking teleologically, we think this factor is the failure to settle on which side the unilateral asymmetrical pattern shall be, when this is developing from the earlier bilateral symmetrical pattern.

The Inferior Vena Cava (I.V.C.). Some of the abdominal veins also develop from a bilateral and symmetrical pattern to one that is unilateral and asymmetrical. The right posterior cardinal vein persists as the termination of the azygos vein, while the left disappears. The right supracardinal vein forms the post-renal segment of the I.V.C., while the left disappears entirely. Part of the right azygos line persists to form all but the termination of the azygos vein, while the left azygos line forms the less important hemiazygos vein.

The inferior caval orifice is derived from the orifice of the embryonic hepatic vein. The I.V.C. itself is a complex structure formed from a number of elements below and the proximal part of the common hepatic vein above. These two parts become joined by new vessels forming between them.

It is, therefore, not difficult to understand why a normal I.V.C. should sometimes be absent when there is partial transposition of the viscera, for the upper part may start to form on the same side as the heart and the lower part on the other side with the abdominal viscera so that no normal junction is possible. All our four cases where there was no structure recognizable as an I.V.C. and where the venous drainage from the lower part of the body, apart from the portal and hepatic veins, was via a large azygos vein to a right or left S.V.C., had partial transposition of the viscera: in both respects there had been a failure in the normal development from the bilateral symmetrical pattern to the unilateral asymmetrical pattern.

\section{The General Picture of a Left-sided Superior Vena Cava}

When there is a superior vena cava on the left, there is usually one on the right also: when the heart and abdominal viscera are normally placed the right S.V.C. enters the right atrium normally and the left also drains into the right atrium through the coronary sinus (Fig. 6-12). We have seen several examples of this in Fallot's tetralogy and other congenital defects. Few of these have come to necropsy except those with complex associated abnormalities. However, one example from a child of seven months is shown in Fig. 4. The coronary sinus was so dilated that at first it was not recognized as such and looked like a large triangular diverticulum of the right atrium. Indeed, it was more like the original left sinus horn, grown greatly in size. The right atrium was 
many times as large as the small left atrium which was displaced upwards and to the left; there was a large atrial septal defect $(17 \times 10 \mathrm{~mm}$.), and great hypertrophy of the right ventricle (Case 45 , Brinton and Campbell, 1953).

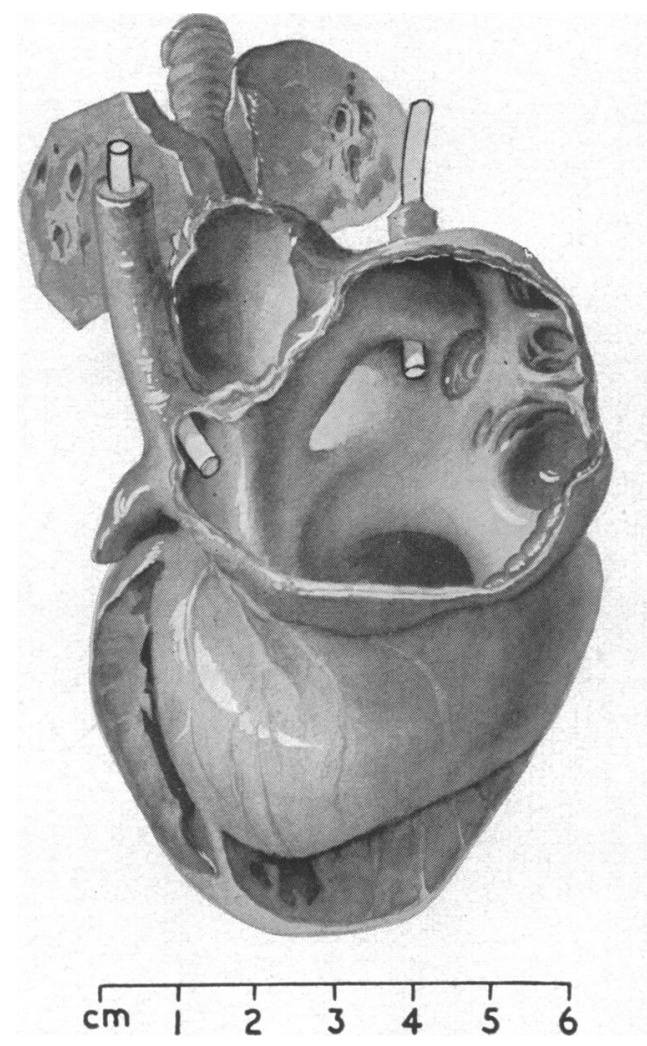

FIG. 4.-The heart with the atria opened and viewed from behind showing bilateral superior venæ cavæ, the right entering the right atrium normally and the left entering an unusually dilated coronary sinus that looks as if it was part of a very large right atrium. The left atrium is pushed upwards and to the left. There was a large atrial septal defect which no doubt further increased the size of the right atrium. Both atria communicated with their respective ventricles but the left was very much smaller than the right. Case 45, Brinton and Campbell (1953).

There are no clinical signs or symptoms to suggest the presence of a left-sided superior vena cava, though sometimes it can be recognized in life by the radiological picture (Brown, 1939). An example is shown in Fig. 5: the pedicle is broad and V-shaped and both sides have a straight border. But this picture is not common and often can not be recognized even when there are known to be bilateral S.V.C., though sometimes one S.V.C. may be seen better if the patient is turned towards the right and the other if he is turned towards the left.

On angiocardiography or cardiac catheterization, however, there is generally no difficulty in recognizing a left superior vena cava, though even then there is some chance about its detection. If the investigation is from the left arm it will probably be seen easily, but if it is from the right arm catheterization is not likely to reveal it and angiocardiography cannot unless there is a cross communication between the right and left S.V.C., and this is far from constant. Even under these conditions, the catheter (Fig. 6A and 10) or the diodone (Fig. 12) after reaching the right atrium may pass up the coronary sinus and so reveal a left S.V.C.

Bilateral S.V.C. may both be demonstrated by angiocardiography. In Fig. $6 \mathrm{~B}$ the left innominate vein makes a wide communication between the two so that both are well displayed and can be seen draining into the right atrium, the left through the coronary sinus. In Fig. 7 the communication is small and only allows a trickle into the right S.V.C., most of the diodone reaching the right atrium through the left S.V.C. and the coronary sinus. In Fig. 8 there is a small vein crossing to 


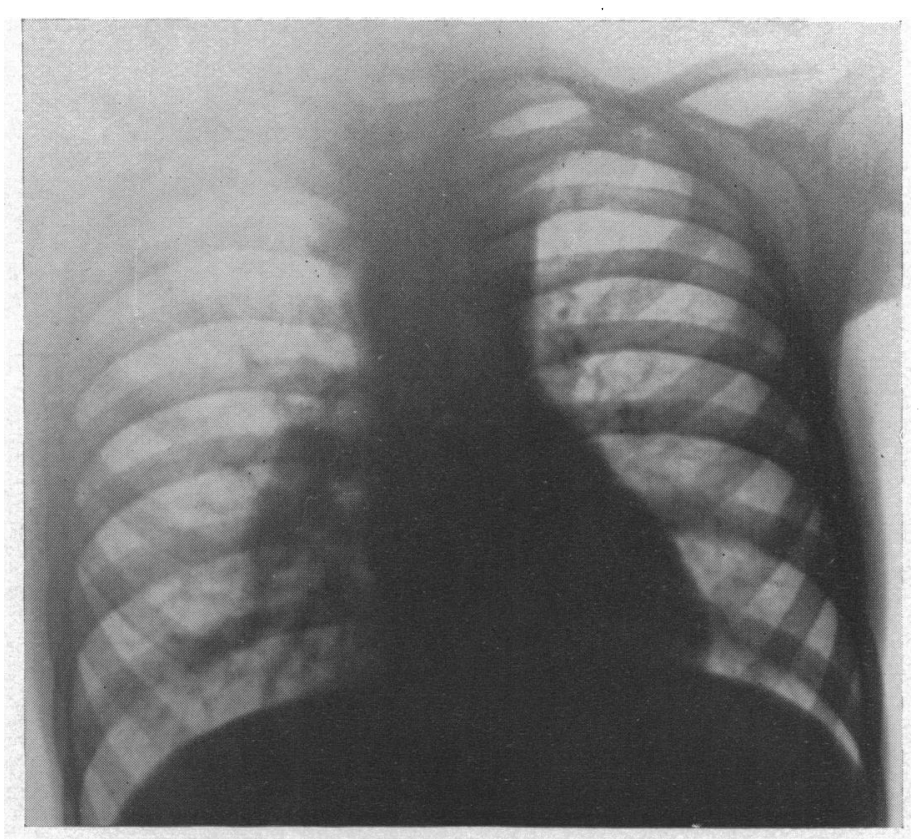

Fig. 5.-Radiograph showing bilateral superior venæ cavæ. The straight borders on both sides of the pedicle giving this a V-shape indicate the presence of S.V.C. on both sides; but most cases do not show this. From a cyanotic patient who had the general picture of Fallot's tetralogy, probably with pulmonary atresia and a patent ductus or other collateral artery on the right side. Case P021.

the right but it does not fill the right S.V.C. which can just be seen below filling from the right atrium and was demonstrated clearly by catheterization.

A left S.V.C. does not as a rule affect the prognosis of the patient's condition or produce a change by which it can be suspected except in these very rare cases where it drains into the left atrium, and so produces a right-to-left shunt (see Case 2, p. 435). Nor does it cause difficulty to the surgeon when operating for whatever associated cardiac condition may be present (Brock, personal communication). When found by chance at operation, it should not be ligated for almost certainly it drains through the coronary sinus into the right atrium: it may be playing an important part in the circulation, for often the communication between the two S.V.C. may be small or absent, though in other cases there may be a large left innominate vein.

Its Influence on Cardiac Catheterization. Generally the presence of a left-sided S.V.C. does not appear to be of great practical importance. This is not so, however, when catheterization is carried out from a vein in the left arm, for there is no doubt that it increases the difficulty of the procedure and may do this in several ways. The angle between the left subclavian vein and a left S.V.C. is much more acute than that between this vein and the normal left innominate vein: this may cause difficulty with the passage of the catheter and may necessitate the use of a vein in the right arm to achieve successful intubation of the heart. Even if the catheter passes down the left S.V.C. and reaches the right atrium, the direction from which it enters this chamber makes it difficult to manipulate it into the right ventricle and the pulmonary trunk. While the catheter tip is in the right atrium it tends to be thrust against the atrial wall by the curve of the coronary sinus so obstructing its orifice and rendering blood sampling very difficult (Fig. 9). If, therefore, this abnormality is known or suspected to be present beforehand it is better to carry out the catheterization through a vein in the right arm. 


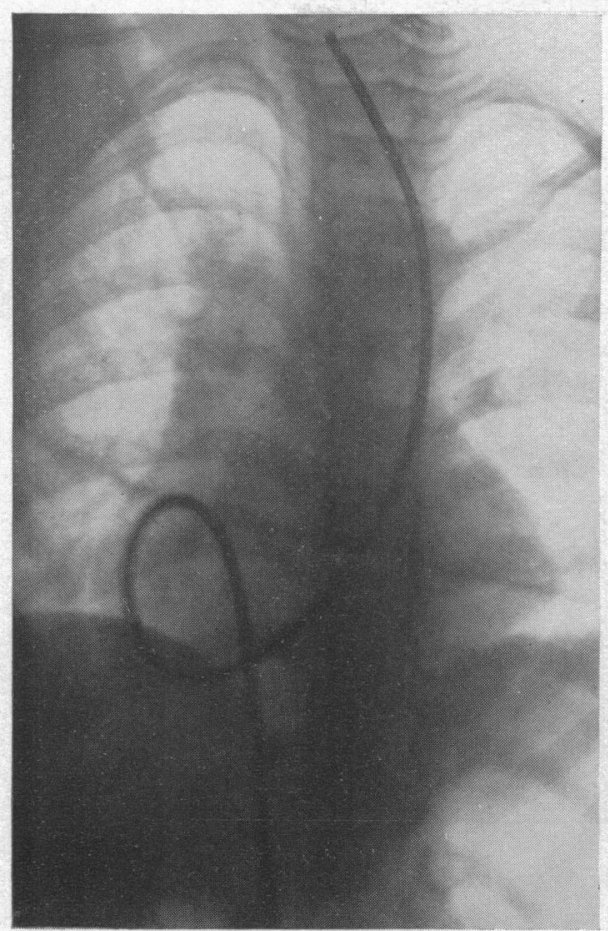

A

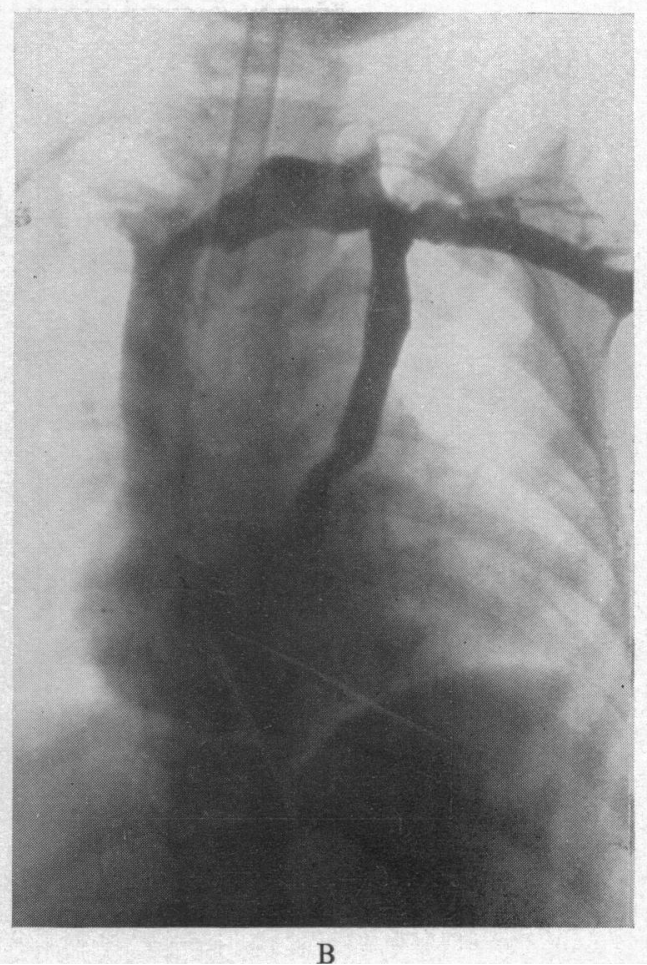

B

FIG. 6.-Bilateral superior venæ cavæ with a large left innominate vein joining the two, the left S.V.C. entering the right atrium through the coronary sinus. (A) The catheter from the inferior vena cava has entered the right atrium and after coiling round in it has passed up the coronary sinus to a left S.V.C. (B) Angiocardiogram showing filling of both S.V.C. and the left innominate vein from the left arm; both S.V.C. enter the right atrium. From a patient with the general picture of Fallot's tetralogy with a severe stenosis (perhaps atresia) and a well marked collateral circulation giving rise to a continuous murmur. The left S.V.C. was seen at operation also when a successful Pott's anastomosis was performed. Case 0683.

Apart from these difficulties, the left S.V.C. may result in two characteristic findings which call for recognition. These are the appearances of the catheter passing down the left S.V.C. if introduced in that direction, or passing up it should the coronary sinus be intubated during exploration of the right atrium entered from some other direction, i.e. from a right S.V.C. (Fig. 10) or from the I.V.C. (Fig. 6A). It is important to realize that the passage of the catheter right across the heart that occurs in these circumstances, with the detection throughout of venous pressures, does not indicate passage through an atrial septal defect.

\section{INCIDENCE OF LEFT-SIDED SUPERIOR VENA CAVA}

In her analysis of 1000 cases examined post mortem, Abbott (1936) found 36 examples of persistent left superior vena cava, of which she classified 9 as major and 27 as minor associated abnomalities. We have found an incidence of about 3 per cent among more than 1500 cases of congenital heart disease, but as many of these have had no special investigations the total is probably much higher than the number we know of.

Search of 200 cardiac catheterization reports, 200 angiocardiograms, and reports of operations upon over 250 patients (these three groups overlapping considerably) revealed 21 examples among our patients at Guy's Hospital, and the other 25 have been noted incidentally. This at first sight suggests a higher incidence than in Abbott's series, but to some extent this may be offset by the fact 


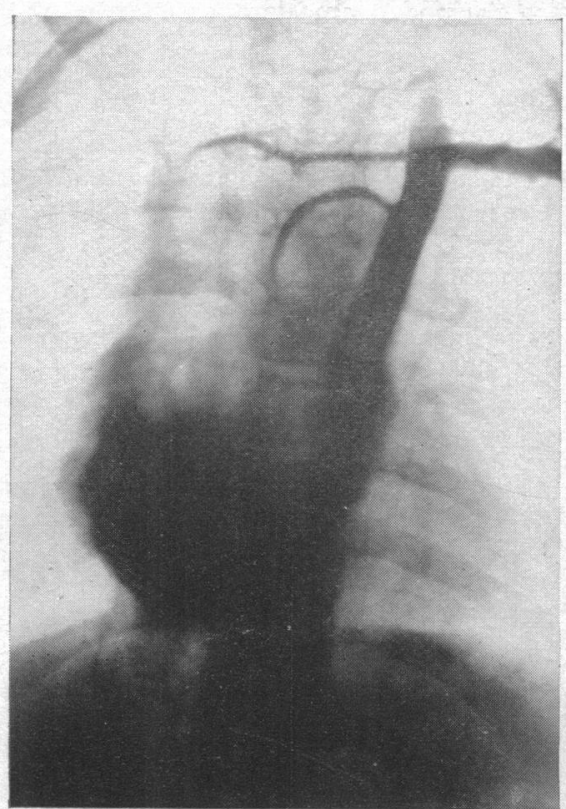

Fig. 7

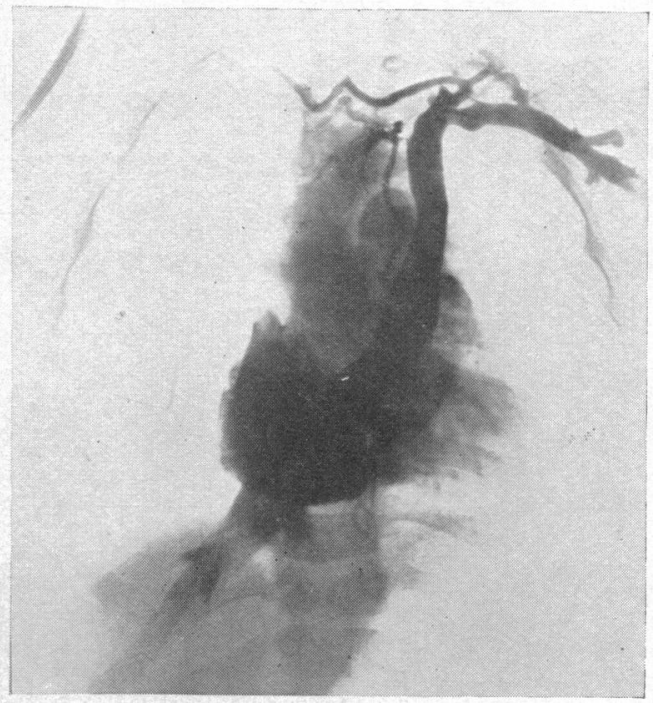

Fig. 8

Fig. 7.-Angiocardiogram showing the main filling of the right atrium through a left superior vena cava and the coronary sinus. There is a small communication through the left innominate vein to the right S.V.C., which can also be seen faintly. Case 0037.

Fig. 8.-Angiocardiogram showing the main filling of the right atrium through a left S.V.C. and the coronary sinus. There is a small communication through the left innominate vein but it does not noticeably fill the right S.V.C., though the lower termination of this seems evident on the right of the figure. Case 1034 .

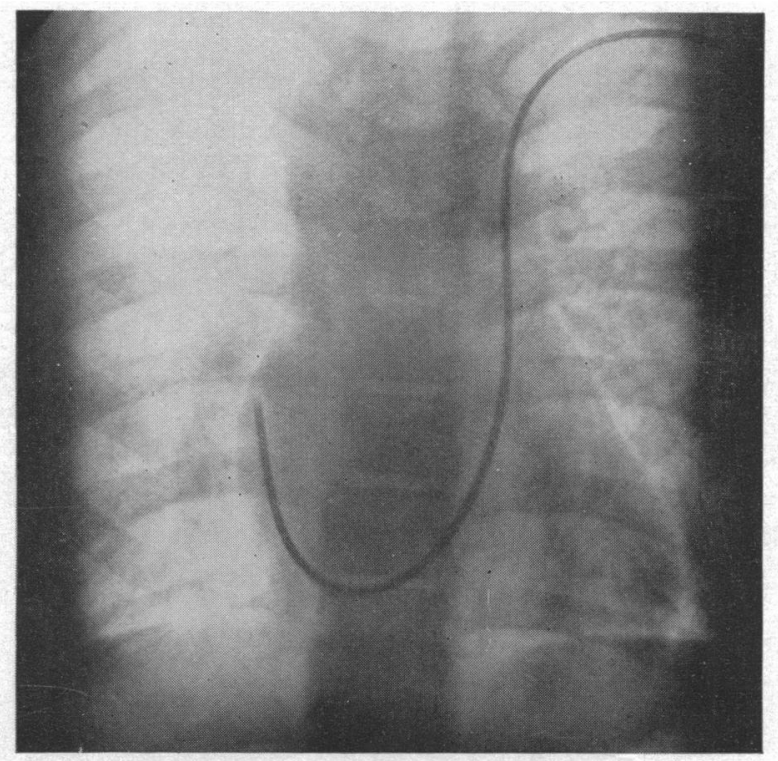

Fig. 9. - The catheter has passed from the left arm down the left superior vena cava and the coronary sinus to enter the right atrium. It is not easy from this position to manipulate the catheter into the right ventricle, as the tip often lies against the right wall, as here. The level at which the catheter passes to the right is low for an atrial septal defect. The left S.V.C. was seen at operation also. From a patient with Fallot's tetralogy. Case 0819. 
that most of our 21 examples were cyanotic and these formed a smaller proportion of Abbott's cases.

Eight of these 21 examples of a left-sided S.V.C. were detected by angiocardiography. In three of the eight the injection was given from the right arm: one was demonstrated by the dye passing across the communication between the two venæ cavæ and then passing down both vessels, one found by cardiac catheterization was shown on angiocardiography by reflux from the right atrium

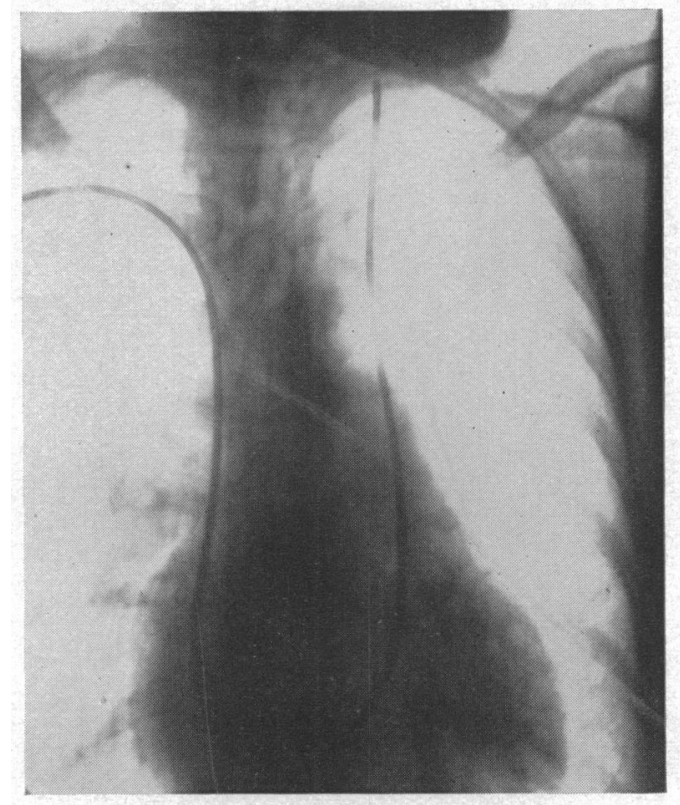

Fig. 10. - The catheter has passed from the right arm down through the right S.V.C. to the right atrium and has passed up the coronary sinus to the left S.V.C. From an acyanotic patient with a left-toright shunt through an atrial septal defect or possibly from pulmonary venous drainage into the right atrium. Case H361.

(Fig. 11 and 12) and the third was shown by angiocardiography and by catheterization but here a right S.V.C. was not demonstrated though it may have been present. These three represent an incidence of less than one in fifty patients injected from the right arm. In the other five the injection was given from a vein of the left arm, making an incidence of about one in seven of patients so injected, which suggests that more examples of this condition might have been found if the left arm rather than the right were used as a routine for angiocardiography, but the cases are very few and almost certainly atypical.

These figures of incidence all refer to patients with congenital heart disease but Sanders (1946) thinks that the incidence of a left-sided S.V.C. is as high as 1 in 350 cadavers, and Papez (1938) found 2 among 635 cadavers dissected.

\section{FINDINGS IN OUR 46 CASES}

We have seen 46 cases with a superior vena cava on the left, and in 30 and probably more of these there was one on the right side also. There was some form of transposition of the thoracic or abdominal viscera in 18 of the 46: this means that over 40 per cent of our cases with dextrocardia and isolated lævocardia had a left-sided S.V.C., but only 2 per cent of over 1500 other cases with congenital heart disease. In the other 28 the heart and abdominal viscera were normally placed and they will be dealt with first as they are somewhat simpler. 


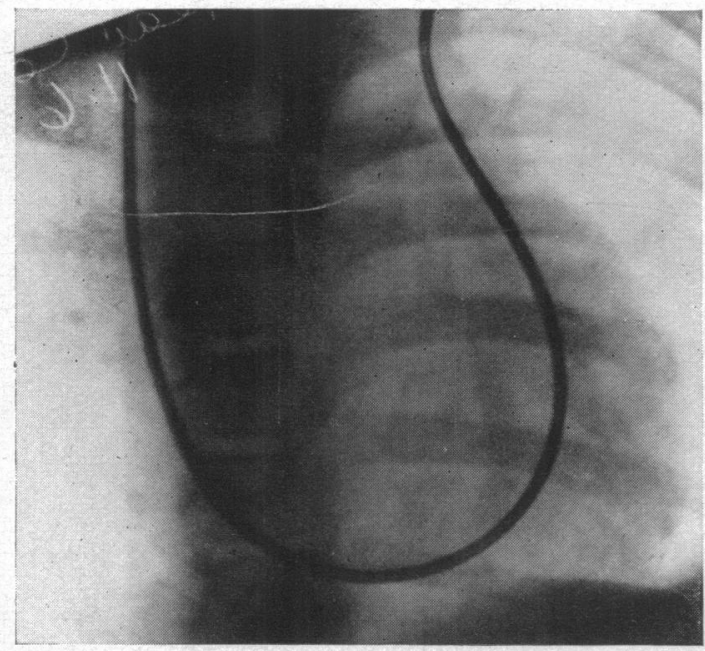

FIG. 11

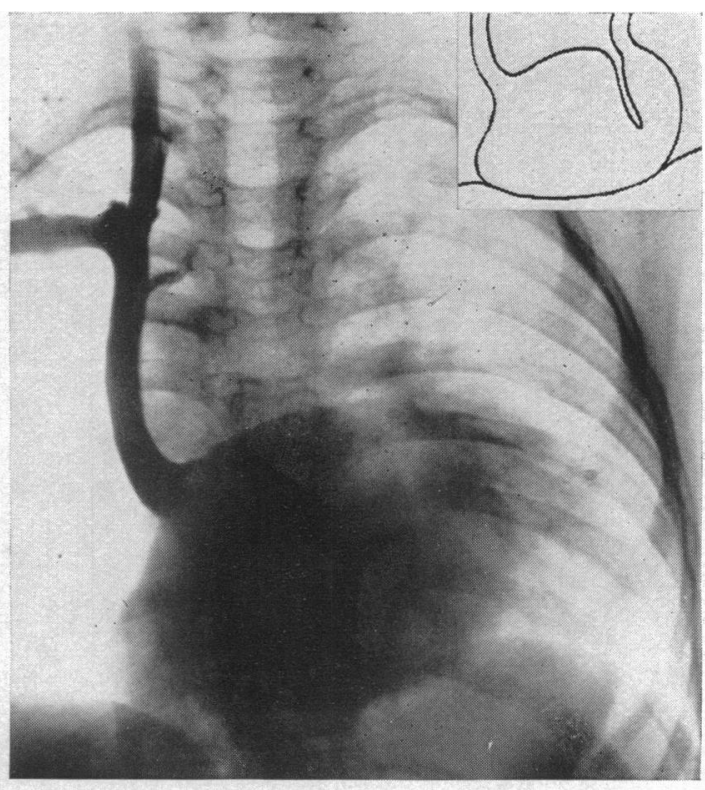

FIG. 12

FIG. 11.-The catheter has passed down a left-sided S.V.C. to the right atrium: after turning across to the right it has passed up a right S.V.C. The position is suggestive of a catheter entering through the coronary sinus and is low for an atrial septal defect. Case 0099.

FIG. 12.-Angiocardiogram showing diodone entering the heart by the right S.V.C. From here it passes across to the left perhaps through an atrial septal defect but below this shadow there is a large broad U-shaped curve that seems to be diodone passing up the coronary sinus to a left S.V.C. Compare Fig. 11, which shows the catheter in this position in the same patient. Case 0099.

\section{With Heart and Abdominal Viscera Normally Placed}

Of these 28 examples of a left-sided superior vena cava 21 had cyanotic and 7 had acyanotic congenital disease (see Table I).

Cyanotic Group. Most of these had Fallot's tetralogy but 14 out of 21 cases is no more than might be expected on its general incidence, especially considering that more of those thought suitable for help by operation had full investigations. Four of these had additional complications: one had a curious rotated heart with apparent evidence of left ventricular preponderance but certainly had pulmonary stenosis, two were thought to have pulmonary atresia and a patent ductus. arteriosus, and one had a heart that was almost bilocular but with the other features of Fallot's. tetralogy (Case 1, see p. 434).

Two others and possibly a third had tricuspid atresisa, one had partial transposition of the main arteries with pulmonary stenosis, one had Eisenmenger's complex, and one was thought to have Ebstein's disease. The last (Case 2) had complicated venous abnormalities with all the pulmonary veins draining into the right atrium.

Of the 21 cyanotic cases, at least 16 had bilateral S.V.C., and probably more, for 4 of the remaining 5 had no special investigations, the left S.V.C. being seen only at operation. The left S.V.C. was thought to drain into the right atrium through the coronary sinus in all but Cases 1 and 2 (see p. 435) though this was not certain, of course, when the vessel was observed at operation only.

Acyanotic Group. Of the 7 cases with acyanotic congenital heart disease, there were atrial septal defects in three and probably in a fourth, and simple pulmonary valvular stenosis with an added left-to-right shunt in the other three: this was from pulmonary veins entering the right atrium in one, from the same cause or from an atrial septal defect in one, and perhaps from an 
TABLE I

Twenty-eight Cases with a Left Superior Vena Cava with the Heart and Abdominal Viscera Normally PLACED

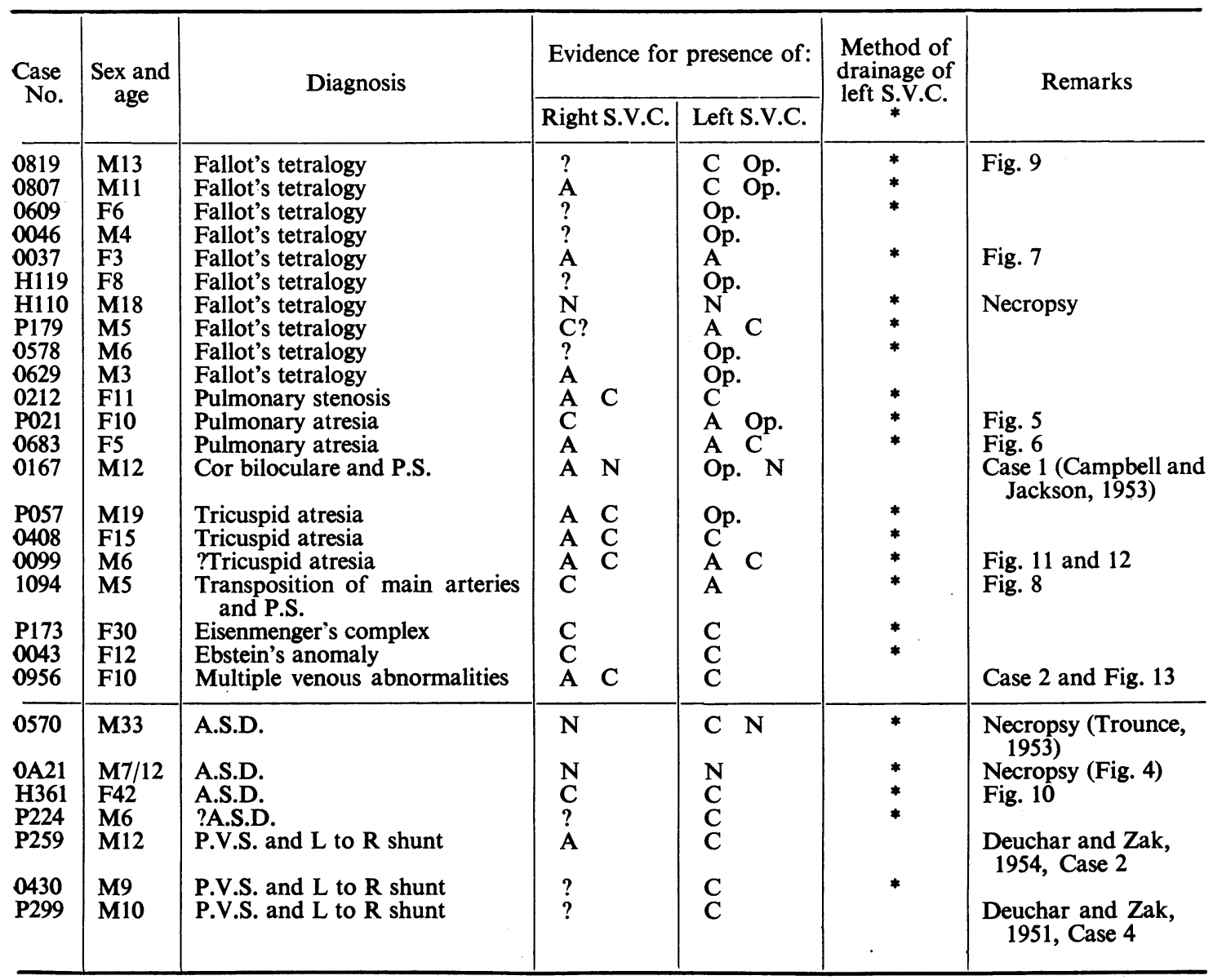

* Indicates that left S.V.C. drains to right atrium through the coronary sinus.

$\mathrm{A}=$ angiocardiography; $\mathrm{C}=$ catheterization; Op.=Operation; $\mathrm{N}=$ necropsy.

aorticpulmonary defect in the third. It is noteworthy that so many of the acyanotic cases should have had a complex combination of lesions.

Four of the seven had bilateral S.V.C., but in the other three the left was the only one that demonstrated. Both were probably present in nearly all, as both were found in the two with necropsy and in the only other who had both angiocardiography and catheterization. In all these seven the left S.V.C. was thought to enter the right atrium through the coronary sinus. Two of these, both with atrial septal defects, had necropsy proof; one is shown in Fig. 4 and the other has been fully reported by Trounce (1953). Two other acyanotic cases are included in the section on dextrocardia, one with and one without transposed viscera.

\section{With the Heart or Abdominal Viscera Transposed (18 Cases)}

The simplest form of left-sided superior vena cava is when the heart and all the abdominal viscera are transposed to form a mirror image of the normal. When the heart is normal, as it usually is in such cases, the left-sided S.V.C. is, of course, the normal one and is generally the only 
one; although this has not been proved in any of the examples we have seen from time to time since none has had any defects that have needed special investigations or has come to necropsy. When, however, the heart has added congenital defects, as in the patients discussed here, an S.V.C. is often found on both sides.

The special problems associated with isolated lævocardia have been discussed by Campbell and Forgacs (1953). The S.V.C. and the venous atrium might be expected to be transposed with the other abdominal viscera as in complete situs inversus, and this often happens; but not always, for sometimes the venous atrium is not transposed with the abdominal viscera and remains on the right side in its normal relationship with the rest of the heart. The cases with dextrocardia are here treated less completely because the same problem of the position of the venous atrium would demand a full discussion of the findings at angiocardiography and catheterization, which it is hoped to deal with in a later paper. We have thought it best to divide these cases according to the nature of the transposition (see Table II).

(1) Isolated Lavocardia with Venous Atrium Transposed to the Left (PI inverted). There were 6 of these-Cases 1-5 of Campbell and Forgacs (1953) and one found subsequently. Here the S.V.C. might be expected to be on the left and this was so in all six cases, and so far as we know none had a S.V.C. on the right (see Table II).

(2) Dextrocardia with Abdominal Viscera Transposed. There were 4 examples of this, all with other congenital defects of the heart and all with an S.V.C. on the left, as expected.

(a) One was acyanotic and catheterization showed the S.V.C., the venous atrium, and the I.V.C. all on the left, but no evidence of a S.V.C. on the right: this follows the pattern of complete situs inversus with a heart that is otherwise normal, but in this case there was a large left-to-right shunt as some or all of the pulmonary veins drained into the left venous atrium.

(b) Three were cyanotic and all had a left-sided S.V.C. and one on the right as well. In two of these the venous atrium was not transposed and the left S.V.C. drained through the coronary sinus into the right atrium; in the third (Case 5, see p. 436) there was no true coronary sinus.

(3) Isolated Lavocardia with Venous Atrium on the Right (PI upright). There were three of these-Cases 7, 9, and 10 of Campbell and Forgacs (1953). Here, as might be expected, all three (and many but not all of the reported cases) had a right-sided S.V.C., but had also a left-sided S.V.C. The left S.V.C. drained into the right atrium through the coronary sinus in two but into the left side of a common atrium in the third (Case 3, see p. 435).

(4) Dextrocardia without Transposed Abdominal Viscera. There were 5 of these and in 4 at least there were again bilateral S.V.C. If the S.V.C. had been single, it is hard to know whether it should be expected on the right or on the left as this would depend on whether the venous atrium was transposed like the rest of the heart or in its normal position like the abdominal viscera. In three the left S.V.C. reached the right atrium through the coronary sinus, in Case 6 it reached the right side of what was practically a single atrium (see p. 436), and in Case 7 it entered the left atrium, but this was probably the transposed venous atrium.

Summary. In the 7 cases of groups 1 and 2(a), where the venous atrium was transposed, the left S.V.C. was thought to be the only one: it went directly into a left venous atrium and the pulmonary veins into a right arterial atrium. This is, we think, the only condition, apart from complete mirror-image situs inversus, in which a lone superior vena cava on the left side is the usual pattern, and Case 1 of Campbell and Forgacs is our only example of such a condition proved by necropsy.

In 34 of the other 39, who generally had bilateral S.V.C., the left was thought to drain through the coronary sinus into the right atrium or occasionally into the right side of a single atrium. The five exceptions, where it drained into the left side of an atrium that was nearly or quite single, will be described shortly. 
TABLE II

Eighteen Cases with a left Superior Vena Cava and Partial Transposition of the Viscera

\begin{tabular}{|c|c|c|c|c|c|c|}
\hline \multirow{2}{*}{$\begin{array}{l}\text { Case } \\
\text { No. }\end{array}$} & \multirow{2}{*}{$\begin{array}{c}\text { Sex and } \\
\text { age }\end{array}$} & \multirow{2}{*}{ Diagnosis } & \multicolumn{2}{|c|}{ Evidence of presence of: } & \multirow{2}{*}{$\begin{array}{c}\text { Method of } \\
\text { drainage } \\
\text { of left } \\
\text { S.V.C. }\end{array}$} & \multirow{2}{*}{ Remarks } \\
\hline & & & Right S.V.C. & Left S.V.C. & & \\
\hline & & \multicolumn{5}{|c|}{ (1) Isolated levocardia with venous atrium transposed to left } \\
\hline 0405 & M3 & Pulmonary stenosis & Absent & $\mathbf{N}$ & $\dagger$ & $\begin{array}{c}\text { Campbell and Forgacs, } \\
1953 \text {, Case } 1\end{array}$ \\
\hline \multirow[t]{2}{*}{$\begin{array}{l}0428 \\
P 105 \\
0556 \\
0266 \\
0 \text { A09 }\end{array}$} & $\begin{array}{l}\text { F19 } \\
\text { M14 } \\
\text { F7 } \\
\text { F5 } \\
\text { M6 }\end{array}$ & $\begin{array}{l}\text { ?Pulmonary stenosis } \\
\text { ? } \\
\text { Pulmonary stenosis } \\
\text { ?Pulmonary stenosis } \\
\text { ?Pulmonary stenosis }\end{array}$ & $\begin{array}{l}\text { ?Absent } \\
\text { ?Absent } \\
\text { ?Absent } \\
\text { ?Absent } \\
\text { ?Absent }\end{array}$ & $\begin{array}{ll}\text { A } & \text { C } \\
\text { A } & C \\
\text { A } & C \\
\text { A } & \text { C } \\
\text { A } & \text { C }\end{array}$ & $\begin{array}{l}\dagger \\
t \\
\dagger \\
+\end{array}$ & \begin{tabular}{|l} 
Case 2 \\
Case 3 \\
Case 4 \\
Case 5
\end{tabular} \\
\hline & & \multicolumn{5}{|c|}{ (2) Dextrocardia with abdominal viscera transposed } \\
\hline $\begin{array}{l}0392 \\
\mathrm{H} 130\end{array}$ & $\begin{array}{l}\text { M20 } \\
\text { M5 }\end{array}$ & $\begin{array}{l}\text { Pulmonary veins to venous atrium } \\
\text { Pulmonary stenosis }\end{array}$ & $\stackrel{\text { ?Absent }}{\mathrm{A}} \mathrm{C}$ & \begin{tabular}{ll|} 
C & \\
A & Op.
\end{tabular} & + & $\begin{array}{l}\text { Acyanotic } \\
\text { Possible pulmonary } \\
\text { atresia }\end{array}$ \\
\hline \multirow[t]{2}{*}{$\begin{array}{l}0330 \\
0347\end{array}$} & $\begin{array}{l}\text { F4 } \\
\text { F12 }\end{array}$ & $\begin{array}{l}\text { Pulmonary stenosis } \\
\text { Pulmonary stenosis }\end{array}$ & $\begin{array}{lll}\mathrm{A} & \mathrm{C} & \mathrm{N}\end{array}$ & $\begin{array}{l}\text { A } \\
\text { A }\end{array}$ & * & Case 5. Absent I.V.C. \\
\hline & & \multicolumn{5}{|c|}{ (3) Isolated lavocardia with venous atrium on the right } \\
\hline $\begin{array}{l}0136 \\
0146\end{array}$ & $\begin{array}{l}\text { M5 } \\
\text { M5 }\end{array}$ & $\begin{array}{l}\text { Cor biloculare, pulmonary atresia } \\
\text { Single atrium and pulmonary } \\
\text { stenosis. }\end{array}$ & $\underset{\text { Op. }}{\mathrm{A}} \stackrel{\mathrm{C}}{\mathrm{N}}$ & $\underset{\text { Op. }}{\mathrm{A}} \mathbf{C} \mathrm{N}$ & $*$ & $\begin{array}{l}\text { Case 4, Absent I.V.C. } \\
\text { Case } 3\end{array}$ \\
\hline \multirow[t]{2}{*}{ H126 } & F8 & Pulmonary stenosis & A C & A & * & $\begin{array}{l}\text { Campbell and Forgacs, } \\
\text { Case } 10\end{array}$ \\
\hline & & \multicolumn{5}{|c|}{ (4) Dextrocardia without transposed abdominal viscera } \\
\hline $\begin{array}{l}0349 \\
0277 \\
\text { P099 } \\
\text { P180 } \\
\text { P321 }\end{array}$ & $\begin{array}{l}\text { F6 } \\
\text { F7 } \\
\text { M9 } \\
\text { M2/12 } \\
\text { M7 }\end{array}$ & $\begin{array}{l}\text { See Case } 7 \\
\text { ?Pulmonary stenosis } \\
\text { ?Slight pulmonary stenosis } \\
\text { See Case } 6 \\
\text { Slight pulmonary stenosis }\end{array}$ & $\begin{array}{ll}? & \\
\text { A } & \text { Op. } \\
\text { A } & \\
\text { N } & \\
\text { C } & \end{array}$ & $\begin{array}{ll}\text { A } & \text { C } \\
\text { Op. } & \\
\text { C } & \\
\text { N } & \\
\text { A } & \text { C }\end{array}$ & $\begin{array}{l}?^{*} \\
* \\
*\end{array}$ & $\begin{array}{l}\text { Case 7. Absent I.V.C. } \\
\text { Case 6. Absent I.V.C. } \\
\text { Acyanotic }\end{array}$ \\
\hline
\end{tabular}

* Indicates that the left S.V.C. was thought to go to the right atrium through the coronary sinus.

$\dagger$ Indicates that the venous atrium, S.V.C., and I.V.C. are on the left side.

$A=$ angiocardiography ; $C=$ catheterization; Op. =operation; $N=$ necropsy.

\section{Cases with Left S.V.C. Draining into Left Side of Atrium}

Generally, the left S.V.C. drains into the right atrium through the coronary sinus. This, however, is not always so and, especially when the atrium is single or almost single, it may drain into the left side, though even then there is sometimes a primitive undeveloped coronary sinus that directs it towards the right side. This happened in five of our cases, two with the heart and abdominal viscera normally placed (Cases 1 and 2) and three with partial transposition (Cases 3 , 6, and 7) and these five will be described shortly. Case 5 is not included here, for though the left S.V.C. entered the left side, it reached a left venous atrium and the right S.V.C. also reached this atrium near the site of the coronary venous ostium: if the coronary sinus had been normally developed the heart would have been simply a mirror image of the usual arrangement when the S.V.C. are bilateral. In three of these and in Case 5, necropsies showed that there was no true coronary sinus. All four had single A-V valves, three had single atria, and two had single ventricles, the other two having large anterior ventricles and small posterior ventricles, the latter having no outlet except through septal defects. In two at least the lungs had three lobes on both sides.

Case 1 had a heart that was almost bilocular but the other features of Fallot's tetralogy. The right S.V.C. entered the right side of the common atrium and the left S.V.C. entered the left side near the point of entrance of the pulmonary veins. He has been fully reported (Campbell and Jackson, 1953). 
Case 2 had complicated venous abnormalities and all the pulmonary veins drained into the right atrium. This was shown by angiocardiography, the diodone entering the right atrium by the right S.V.C. and producing striking filling of the four pulmonary veins at $1 \mathrm{sec}$. (Fig. 13). The aorta filled at $2 \mathrm{sec}$. before the pulmonary arteries and no re-filling of the pulmonary veins was seen up to $6 \mathrm{sec}$. On catheterization, the two S.V.C. drained into the two sides of what seemed to be a large single atrium but the difference in the $\mathrm{O}_{2}$ content (R.A. $86 \%$, L.A. 67\%) was enough to suggest that they were separate chambers. The drainage of the left S.V.C. to the left atrium may have been partly the cause of the central cyanosis but probably there was transposition of the aorta and pulmonary trunk. The heart itself and the stomach were in the normal position, but physical and X-ray examination suggested that the liver was on both sides, so that possibly she should be included among those with partial transposition.

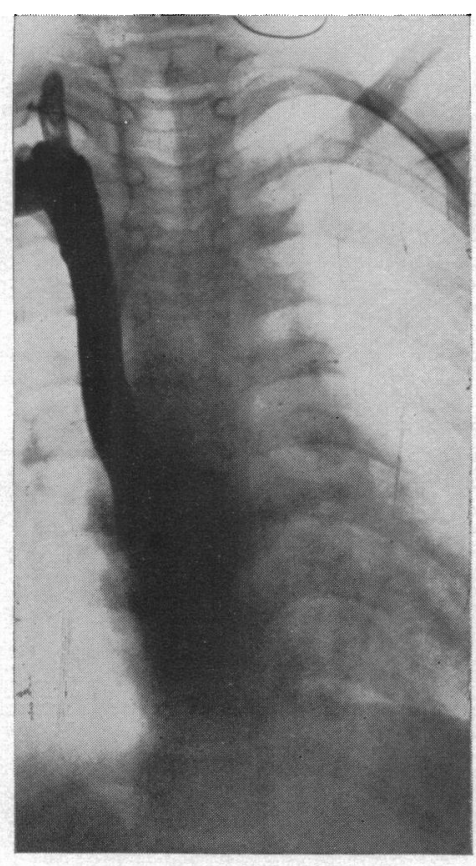

A

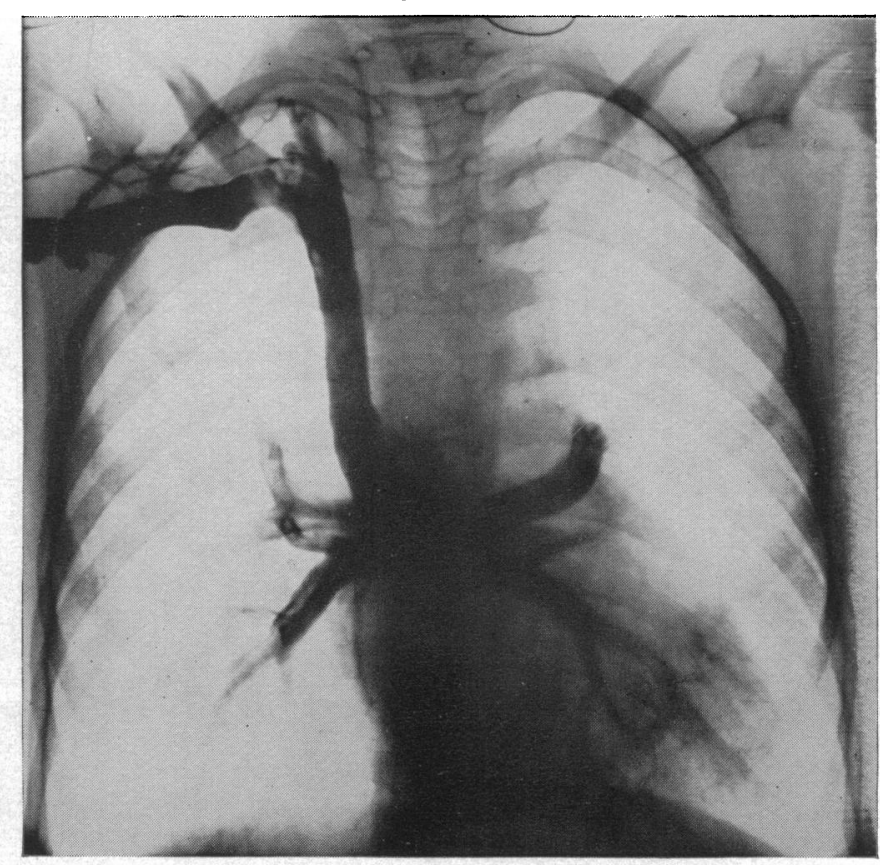

B

Fig. 13.-Angiocardiogram showing the four pulmonary veins and the right S.V.C. draining into the right atrium. (A) at $\frac{1}{2} \mathrm{sec}$., and (B) at $1 \mathrm{sec}$. after the injection of diodone. Case 2.

Case 3 has been described (Campbell and Forgacs, 1953, Case 9) as an example of lævocardia with transposed viscera: the heart just pointed to the left but was very central, and the stomach was transposed though the liver was almost equally on both sides. As in Case 1, the right S.V.C. entered the common atrium on the right and the left entered on the left side near the point of entry of the pulmonary veins.

The other two (Cases 6 and 7) are described in the next section on absence of the inferior vena cava.

\section{Absence of the INFERIor Vena Cava}

We have seen 4 cases where there was no true inferior vena cava and blood from the lower part of the body, apart from the portal and hepatic veins, flowed through a large azygos vein to a right or left S.V.C. and so to the atrium. All had a left-sided S.V.C. and three, at least had one on the right as well. In one the diagnosis was made by angiocardiography, in one by catheterization, and in one by both methods. In two of these three it was proved by necropsy: in the fourth, who died when ten weeks old, no special investigations had been carried out and the condition was found at necropsy.

All had other complex congenital defects of the heart. Of the three with necropsies, two had single atria and the third a large atrial septal defect; one had a single ventricle and two had large anterior and small posterior ventricles, the only exit from the latter being through ventricular septal 
defects. All had pulmonary stenosis or atresia. In two of these three and probably in the fourth there was a patent ductus arteriosus, and the fourth, who was the least disabled, was thought to have an increased blood flow to the lungs.

All four had some degree of transposition of the viscera. The first had the heart on the left but the abdominal viscera transposed. The other three had dextrocardia, one with and two without the abdominal viscera transposed (so that in the former the rest of the development could have been normal). When the heart was on the left, the azygos vein drained to a right S.V.C.; and when the heart was transposed to the right, it drained to a left S.V.C., though one might have expected a relationship to the position of the abdominal viscera rather than of the heart. Most other features were too variable from case to case for any generalization. These four cases will be described shortly.

Case 4 had a bilocular heart, pulmonary atresia, and a patent ductus arteriosus on the left side. The heart was on the left but the abdominal viscera were transposed; a large azygos vein on the right drained all the lower part of the body except the portal and hepatic veins, and passed to the right S.V.C. and so to the right side of the common atrium. He has been fully reported by Campbell et. al. (1952) and a characteristic picture of diodone passing up the right side behind the heart to the right S.V.C. is shown in their Fig. 4. There was a left S.V.C. also and this passed through the coronary sinus to the right side of the common atrium.

Case 5 died when he was 6 years old after pulmonary valvotomy. The heart and abdominal viscera were both transposed but there were other congenital abnormalities that produced central cyanosis. The left S.V.C. received a large azygos vein that drained the abdominal and common iliac veins, and entered the left (venous) atrium. The right S.V.C. crossed behind the right (arterial) atrium and terminated at the site of the coronary venous ostium in the left atrium. The pulmonary veins drained into the right (arterial) atrium. From here the blood passed through a large atrial septal defect to the left atrium, whence it passed through a common A-V valve to a large anterior ventricle: both the aorta and the pulmonary trunk arose from this. The small posterior ventricle had no outlet except through a ventricular septal defect.

Case 6 died when he was 10 weeks old. The heart was on the right but the abdominal viscera were not transposed. The left S.V.C. and the hepatic vein entered the left side of the atrium. The drainage from the rest of the lower part of the body was through a large azygos vein which entered this left S.V.C. The right S.V.C. and the pulmonary veins entered the right side of the atrium and continued as a channel behind a valve-like flap (? representing an undeveloped coronary sinus) towards the left side of the atrium. The two sides formed virtually a single atrium and blood passed through a common $A-V$ valve to a ventricle that lay on the left and anteriorly. Both the small pulmonary trunk and the larger aorta arose from this ventricle. A large ventricular septal defect formed the only communication with the second smaller ventricle.

Case 7 is still in good health. A girl, aged 6, had been somewhat cyanosed from birth but was not much disabled as she could walk up to two miles. The heart was very large (c.t.r. 64) and was on the right but the liver and stomach were normally placed. A loud continuous murmur was heard widely over the right side, but the pulse pressure was only 95/70. The large pulsatile arteries and the pleonæmic lungs suggested an increased pulmonary blood flow.

On angiocardiography, diodone passed down a left S.V.C. (without any obvious cross communication to a right S.V.C.) to a venous atrium on the left. On catheterization, both internal jugular veins were intubated but no S.V.C. could be entered. From the right saphenous vein the catheter passed up the left side, presumably up an azygos vein, and then down a left S.V.C. into a left-sided atrium. There was pulmonary hypertension and the pulmonary flow was double the normal.

\section{Discussion}

Most of the earlier examples of a left-sided superior vena cava were found at necropsy or in the dissecting room. McCotter (1916) has written one of the best summaries: adding together three of his own cases and others that had been reported, he found 120 cases with a persistent left S.V.C. and classified them in four groups (see Table III), the first three all having bilateral S.V.C. (96 cases) and the fourth having a lone left S.V.C. (12 cases only). His first group consisted of those with a double S.V.C. without any communication between them and included 64 cases or more than half the total. His Case 1, a woman, aged 35, who had no other abnormalities of the heart was an example of this group: both S.V.C. received an azygos vein.

His second and third groups were about equal in size and consisted of 32 cases where there 
TABLE III

Analysis of 120 Reported Cases with a left Superior Vena Cava After McCotter (1916)

\begin{tabular}{|c|c|c|c|}
\hline & $\begin{array}{l}\text { Adults (44) and } \\
\text { children (7) }\end{array}$ & $\begin{array}{l}\text { New-born and } \\
\text { fotuses and of } \\
\text { unknown age }\end{array}$ & Total \\
\hline $\begin{array}{l}\text { Double S.V.C. with no communication ... } \\
\text { Double S.V.C. with small communications } \\
\text { Double S.V.C. with a communication } \\
\text { Left S.V.C. without right S.V.C. . . } \\
\text { Persistent left S.V.C. unclassified }\end{array}$ & $\begin{array}{r}22 \\
12 \\
9 \\
6 \\
2\end{array}$ & $\begin{array}{r}42 \\
2 \\
9 \\
6 \\
10\end{array}$ & $\begin{array}{l}64 \\
14 \\
18 \\
12 \\
12\end{array}$ \\
\hline Total & 51 & 69 & 120 \\
\hline
\end{tabular}

were double S.V.C. with a normal or with a small communication between them. The smaller communications were more common in the adults, so perhaps some of the infants classed as having no communication might have developed one later had they lived. His Case 2, a man, aged 45, whose heart was large but otherwise normal, belonged to this group.

His fourth group consisted of 12 cases where the left S.V.C. was the only one present and he had no personal example of this. Smith (1916) reported one and found reports of 13 others: certainly in his case and probably in the others the left S.V.C. (although it was the only one) drained into the coronary sinus and so into the right atrium.

McCotter did not find any convincing account of a left S.V.C. terminating in the left atrium, though more recently Young and Griswold (1951) thought this happened in their Case 4 and Diaz and Anido (1949) reported one where ligation of the left S.V.C. seemed to benefit the patient and reduce his cyanosis. Brown (1950) quotes some examples and Silvestre (1952) states that it may occur as an isolated malformation.

McCotter does not list a special group where the pulmonary veins drain into the left S.V.C. and across by the innominate vein to the right side and so into the right atrium. But his Case 3 , a man, aged 57, had these features and was classified in his third group, so it is not clear how many of the 18 cases in this group may have had this abnormality also.

Chouke (1939) described a single case of bilateral S.V.C. in a man, aged 50, with no other abnormality than atrophic testes, and found more reported since McCotter's paper, bringing the total to over 200 cases. Although he lists these, he does not classify them or add anything about the different types.

As has been stated, most of the earlier examples were found at necropsy or in the dissecting room by examination of the cadaver, but Lam (1945) reported that he had seen a left S.V.C. during an operation for patent ductus arteriosus and De Groot (1951), describing an unusual case of patent ductus arteriosus and bilateral S.V.C., mentioned having seen a left S.V.C. during operations for pulmonary stenosis.

It is, however, the increasing use of cardiac catheterization and of angiocardiography that has focused interest on these conditions and led to a much larger number being discovered. Having been demonstrated by one of these methods, it may occasionally be recognized in retrospect on the plain radiograph of the chest as a faint shadow with a straight border running down against the left side of the upper mediastinum (Fig. 5), but this is rarely pathognomonic.

Cournand et al. (1949) and Friedlich et al. (1950) appear to have been the first to describe the appearance of passing a cardiac catheter along a left S.V.C., and cases recognized by angiocardiography were reported by Gordon et al., by Cooley et al., and by Campbell and Hills, all in 1950. Castellanos (1951) and his associates had seen 41 cases and Brantigan (1947), Young (1947), Edwards and Du Shane (1950), and Edwards (1951) have reported some interesting types of venous abnormalities. Berri et al. (1952) have found a left S.V.C. opening into the right atrium through the coronary sinus in 3 of 19 cases of Fallot's tetralogy. Steinberg et al. (1953) 
have reported 11 cases, many of which were associated with complex cardiac abnormalities, including two with transposition of the viscera; but it is interesting that four of their cases had, so far as was known, no other congenital abnormality and among these four was the only example of a lone left S.V.C.

\section{SumMARY AND CONCLUSIONS}

A left-sided superior vena cava is not rare in cases of congenital heart disease. We have found one present in 46 cases-in 2 per cent of those with the heart and abdominal viscera in their normal position ( 28 cases) and in 40 per cent of those with some degree of transposition of the viscera (18 cases).

When there is mirror-image dextrocardia and situs inversus, the S.V.C. is, of course, on the left side, and is then the only one. In seven of our cases of incomplete transposition of the viscera, the S.V.C. was, we think, of this type: most of these had lævocardia with transposition of the abdominal viscera (Group 1).

More often, even when there is partial transposition of the viscera, there is a S.V.C. on the right as well as on the left, the right draining into the right (venous) atrium normally, and the left reaching the same atrium through the coronary sinus. This demands no great change in the normal embryological development-only that the upper part of the left anterior cardinal vein does not become obliterated. Most of our cases appeared to be of this type, 34 of the 39 where there was not thought to be a lone S.V.C., and in at least 26 of the 34 the S.V.C. was bilateral.

In the remaining five cases the right S.V.C. drained into the right side and the left S.V.C. into the left side of an atrium that was without an interatrial septum or at least with a large atrial septal defect. This means an arrest of normal development at an earlier stage, for there has been no normal division of the two atria, no normal absorption of the sinus venosus into the right atrium, and no normal development of the coronary sinus, for the left anterior cardinal vein and the left sinus horn have remained in a more primitive state.

We have seen no example of a left S.V.C. draining into an otherwise normal left atrium and producing a right-to-left shunt.

In two of the five cases with the left S.V.C. draining into the left side of an atrium that was generally single, and in two others, there was no inferior vena cava and blood from all the lower part of the body, except that flowing through the portal and hepatic veins, passed up an azygos vein to a right or left superior vena cava and so to the atrium. All had some degree of transposition of the viscera.

The presence of a left superior vena cava and the absence of the inferior vena cava are both more common when there is partial transposition of the viscera. This is partly explained by a failure of the normal development from the symmetrical bilateral pattern of the veins to the asymmetrical unilateral pattern in all three conditions.

Until the last few years a left-sided superior vena cava was observed mainly in the post-mortem and dissecting rooms, but the increasing use of angiocardiography and cardiac catheterization has led to its more frequent detection in life and most of our cases were found in this way.

The presence of an S.V.C. on the left side does not, as a rule, seem to be of much practical importance. If, however, its presence is suspected, catheterization is better carried out from the right arm, as it may prove difficult after entering the atrium from the left S V.C. and the coronary sinus. When a left S.V.C. is found at operation it should not be ligated as probably it drains into the right atrium through the coronary sinus.

We are grateful to Professor T. B. Johnston for some guidance but he cannot be held responsible for the views expressed. We also wish to thank several colleagues for help-with operations, with angiocardiography, and with catheterization.

A forty-seventh case has been found since this was completed. There was a ventricular septal defect with an over-riding aorta but he was acyanotic until terminally. The left S.V.C. drained through the coronary sinus into the right atrium. 


\section{REFERENCES}

Abbott, M. E. (1936). Atlas of Congenital Cardiac Disease. New York.

Berri, G. C., Caprile, J. A., and Kreutzer, R. (1952). Arch. Mal. Creur, 45, 1082.

Brantigan, O. C. (1947). Surg. Gynec. Obstet., 84, 653.

Brinton, W. D., and Campbell, M. (1953). Brit. Heart J., 15, 335.

Brody, H. (1942). Arch. Path., 33, 221.

Brown, J. W. (1939). Congenital Heart Disease. 1st ed., London. (1950). Congenital Heart Disease. 2nd ed. Staples, Press, London.

Campbell, M., and Forgacs, P. (1953). Brit. Heart J., 15, 401.

-, and Hills, T. H. (1950). Brit. Heart J., 12, 65.

-, and Jackson, J. W. (1953). Guy's Hosp. Rep., 102, 337.

Castellanos, A. (1951). Arch. Med. Infantil., 20, 191.

Chouke, K. S. (1939). Anat. Rec., 74, 151.

Cooley, R. M., Sloan, R. D., Harden, C. R., and Bahnson, H. J. (1950). Radiology, 54, 848.

Cournand, A., Baldwin, J. S., and Himmelstein, A. (1949). Cardiac Catheterization in Congenital Heart Disease. Commonwealth Fund, New York.

de Groot, J. W. C. (1951). Brit. Heart J., 13, 403.

Deuchar, D. C., and Zak, G. A. (1951). Guy's Hosp. Rep., 101, 1.

Diaz, A. R., and Anido, H. (1949). Diseases of the Chest, 15, 684.

Edwards, J. E. (1951). Arch. Path., 51, 446.

(1953). Proc. Staff Meetings Mayo Clinic, 28, 114.

- and Du Shane, J. W. (1950). Arch. Path., 49, 517.

Friedlich, A. L., Bing, R. J., and Blount, S. G., Jr. (1950). Bull. Johns Hopkins Hosp., 86, 20.

Gardner, F., and Oram, S. (1953). Brit. Heart J., 15, 305.

Gordon, A. J., Brahms, S., and Sussman, M. L. (1950). Amer. Heart J., 39, 114.

Lam, C. R. (1945). J. Thorac. Surg., 14, 393.

McCotter, R. E. (1916). Anat. Rec., 10, 371.

Papez, J. W. (1938). Anat. Rec., 70, 191.

Sanders, J. M. (1946). Anat. Rec., 94, 657.

Silvestre, J. (1952), in Soulie, P., Cardiopathies Congenitales. L'Expansion Scientific Française.

Smith, J. C. (1951). Amer. Heart J., 41, 561.

Smith, W. C. (1916). Anat. Rec., 11, 191.

Snellen, H. A., and Albers, F. H. (1952). Circulation, 6, 801.

Steinberg, I., Dubilier, W., and Lukas, D. S. (1953). Diseases of the Chest, 24, 479.

Swan, H. J. C., Burchell, H. B., and Wood, E. H. (1953). Proc. Staff Meetings Mayo Clinic, 28, 452.

Trounce, J. R. (1953). Guy's Hosp. Rep., 102, 140.

Whitaker, W. (1954). Brit. Heart J., 16, 177.

Young, M. O. (1947). Arch. Path., 44, 169.

Young, M. D., and Griswold, H. W. (1951). Circulation, 3, 202. 